\title{
The effect of royal jelly on boar sperm viability and motility during liquid storage for 96 hours
}

\author{
Aiste Iljenkaite, Sigita Kerziene, Agila Dauksiene, Zoja Mikniene, \\ Henrikas Zilinskas, Neringa Sutkeviciene
}

Lithuanian University of Health Sciences, Veterinary Academy, Kaunas, Lithuania

Received November 7, 2019

Accepted January 28, 2020

\begin{abstract}
The current study was carried out to investigate the protective effects of royal jelly supplementation on sperm motility, viability and $\mathrm{pH}$ value during the liquid storage of boar semen at $16{ }^{\circ} \mathrm{C}$ and $4{ }^{\circ} \mathrm{C}$, at various periods of time $(0,24,48,72$ and $96 \mathrm{~h})$. Semen samples were collected from 11 boars, diluted with a long-term extender and supplemented with different concentration of royal jelly $(0 \%, 0.5 \%, 1 \%$ and $2 \%)$ at a final concentration of $50 \times 10^{6} \mathrm{sperm} / \mathrm{ml}$. In the laboratory, the semen was assessed for sperm morphology, viability (eosin-nigrosin staining), subjective motility and objective sperm motility by sperm class analyzer. In total, 396 tests for sperm viability and motility were performed. The longer storage time and the lower incubation temperature showed lower sperm motility and viability results. The results showed that royal jelly supplementation at $1 \%$ concentrations protected the functionality of the sperm plasma membrane during the liquid storage time of $96 \mathrm{~h}$ at $16^{\circ} \mathrm{C}$. Sperm subjective and objective motility results in samples stored at $4{ }^{\circ} \mathrm{C}$ decreased with higher royal jelly concentrations and longer storage time, and differ significantly from the results in samples stored at $16{ }^{\circ} \mathrm{C}$ $(P<0.05)$. Our data showed that royal jelly supplementation at lower concentrations can improve boar semen motility and viability parameters during liquid storage at $16{ }^{\circ} \mathrm{C}$ for $96 \mathrm{~h}$.
\end{abstract}

Honey bee products, porcine semen quality

In the swine industry, the use of artificial insemination is over 90\%. Usually, artificial insemination with fresh semen is performed after dilution or keeping for some days (2-14 days, depending on the composition of diluents) at $15-20{ }^{\circ} \mathrm{C}$, using a dose of $3-5 \times 10^{9}$ spermatozoa at a volume of $80-100 \mathrm{ml}$ (Kaeoket et al. 2010). Seminal doses are diluted in commercial extenders that provide an energy source, ensure a proper $\mathrm{pH}$ value and osmotic pressure, protect spermatozoa against thermal shock and inhibit bacterial growth (Estienne et al. 2007; Pinart et al. 2015). A wide range of commercial extenders have been developed for optimal preservation of stored boar semen, however, most insemination is performed within 3 days of collection because the fertility of extended semen gradually deteriorates with the increase in storage time, probably related to oxidative stress during storage and the litter size is known to decrease when the semen used was stored for more than 4 days (Johnson et al. 2000; Sutkeviciene et al. 2018). Antioxidants are substances that inhibit oxidation and ultimately cell damage by neutralising free radicals (Petruska et al. 2014). There are reports indicating that the supplementation of extenders with antioxidants such as taurine, glutathione, trehalose, L-carnitine, vitamin E analogue Trolox successfully reduced the negative impact of different oxidants which were produced during sperm dilution and storage (Bucak and Tekin 2007; Vongpralub et al. 2016; Allai et al. 2018).

Royal jelly is gluten secreted by hypopharyngeal and submandibular glands of young worker bees (6-12 days of life) of the species Apis mellifera (Kamakura et al. 2001; Nakajima et al. 2009). It is an essential nutrient for young (1-3 days) bees and queens,

Address for correspondence:

Neringa Sutkeviciene

Veterinary Academy

Lithuanian University of Health Sciences

Tilzes str. 18, LT-47181, Kaunas, Lithuania

Phone: +37037363318

E-mail: neringa.sutkeviciene $@$ lsmuni.lt

http://actavet.vfu.cz/ 
playing a very important role in the queen's feeding. The queen can survive for up to 6-7 years using the royal jelly, while the worker bees live between 7-8 weeks in the active season (Morita et al. 2012). Royal jelly is mainly made of water (60-70\%), proteins (12-15\%), sugars, lipids (including sterols and fatty acids), small amounts of mineral salts, vitamins, natural hormones, some enzymes, antibacterial and antibiotic components (Hattori et al. 2007; Moradi et al. 2013). Chemical analysis has shown that royal jelly exhibits antioxidant properties, due to its richness of a large number of bioactive substances, including 10-hydroxy-2-decenoic acid (10-HDA), phenols or vitamin E (Petelin et al. 2019). Several other analytical and pharmacological studies demonstrated that royal jelly contains also numerous essential amino acids with pharmacological effects such as vasodilatation, hypotension, anti-hypercholesterolaemic, antioxidant, anti-fatigue, insulin-like and estrogenic, hypoglycaemic and anti-inflammatory effects (Kamakura et al. 2001; Matsui et al. 2002; Moradi et al. 2013). It has also been shown that royal jelly has different types of biological activity in various cells and tissues of animal models (Hashimoto et al. 2005).

A successful effect of royal jelly supplementation on sperm quality and fertilizing ability has been reported in a laboratory model and domestic animals (Abd-Allah 2012; Moradi et al. 2013; Zahmatkesh et al. 2014; Amirshahi et al. 2014; Ghanbari et al. 2015; Ahmadnia et al. 2015; Shahzad et al. 2016). Also, a few studies have examined the effect of royal jelly cryopreservation and incubation resilience of goat semen (Alcay et al. 2017).

Previous studies have demonstrated that the physical properties and chemical composition of royal jelly are dependent on storage conditions. The storage of royal jelly at room temperature increases viscosity, acidity and protein degradation, although no compositional change was observed during storage at $4{ }^{\circ} \mathrm{C}$ (Kamakura et al. 2001). The current study was carried out to investigate the protective effects of royal jelly supplementation on the boar sperm motility, viability and $\mathrm{pH}$ during liquid storage.

\section{Experimental design}

\section{Materials and Methods}

Ejaculates were collected at a commercial artificial insemination centre on a routine basis with a standardized protocol once per week. The ejaculate was diluted with Vitasem (Magapor, Spain) long-term extender until the final sperm concentration of 2 billion sperm cells per dose. Just after dilution and bottling one dose was refilled and divided into four tubes (each tube at a volume of $20 \mathrm{ml}$ ) with the addition of the final royal jelly concentration - $0 \%$ (control), $0.5 \%, 1 \%$ and $2 \%$. Raw royal jelly was obtained from beekeeper A.A. and kept at $-20{ }^{\circ} \mathrm{C} \pm 2{ }^{\circ} \mathrm{C}$ before use. On the day of the test, royal jelly was defrosted and divided into tubes at a final concentration. In one hour tubes supplemented with royal jelly were delivered to the laboratory in an acclimatized transport box $\left(16{ }^{\circ} \mathrm{C} \pm 2{ }^{\circ} \mathrm{C}\right)$ and were used for primarily $(0 \mathrm{~h})$ sperm motility, viability, $\mathrm{pH}$, concentration and morphology examination. Only those samples having more than $75 \%$ motility and more than $75 \%$ normal sperm were used for further experiments. All samples were once again divided into two parts (each tube at a volume of $10 \mathrm{ml}$ ) and into two tubes $2 \times 5 \mathrm{ml}$. One part of the samples (Group 1) was incubated at $16^{\circ} \mathrm{C} \pm 2{ }^{\circ} \mathrm{C}$ in the acclimatized box (Friocell, Germany) and the second part of the samples (Group 2) was kept at $4{ }^{\circ} \mathrm{C} \pm 2{ }^{\circ} \mathrm{C}$ in a refrigerator (Eiron, Latvia) for $96 \mathrm{~h}$. Sperm viability, $\mathrm{pH}$, subjective motility and objective motility were checked after 24, 48, 72 and $96 \mathrm{~h}$ of incubation. In total, 396 tests were performed.

Sperm concentration and morphology of diluted chilled boar semen were assessed using conventional semen evaluation methods (Januskauskas 2010). Sperm viability was detected using eosin-nigrosin staining (Minitube, Germany) and sperm $\mathrm{pH}$ value was analyzed by an electronic $\mathrm{pH}$ meter (AB150, Fisher Scientific Accumet $^{\mathbb{R}}$, USA) according to the manufacturer's instructions. Motility of spermatozoa was assessed in two ways: subjectively by microscope and objectively computer (Sperm Class Analyzer, Microptic, Spain). Motility of spermatozoa was examined subjectively by eyes at $37{ }^{\circ} \mathrm{C}$ under a phase-contrast microscope $\mathrm{Olympus} \mathrm{BH} 2$ with a pre-warmed $37^{\circ} \mathrm{C}$ stage (Olympus Optical Co., Ltd., Japan) using $\times 400$ magnification. Motility was analyzed on $5-\mu 1$ aliquots of semen. The samples were prewarmed in a $37^{\circ} \mathrm{C}$ water bath (Memmert, Germany) for $5 \mathrm{~min}$ before analysis. Objective motility was analyzed by the Sperm Class Analyzer program. At least 1500 cells in one sample were analyzed and the objective motility by percents was fixed.

Statistical analysis was performed using the SPSS Statistics Version 25 (IBM, USA). The data included in the model were analyzed using descriptive statistics (mean \pm SD) and -way ANOVA analysis. The differences 
between the investigated groups were analyzed by the LSD method $(\alpha=5 \%)$. The differences were considered to be significant when $P<0.05$. The correlation between the dependent variables and the strength of the direct relation was evaluated by Pearson's correlation coefficients.

\section{Results}

The test of sperm viability, eosin-nigrosin staining showed that supplemented royal jelly at $0.5-1 \%$ concentrations was able to protect the functionality of sperm plasma membrane during the liquid storage time of $96 \mathrm{~h}$ at a $16^{\circ} \mathrm{C}$. As shown in Fig. 1, the highest protective effect of royal jelly was found at the $1 \%$ concentration during the storage time of $96 \mathrm{~h}$ at $16{ }^{\circ} \mathrm{C}$. However, the liquid storage of semen supplemented with royal jelly at $4{ }^{\circ} \mathrm{C}$ had no protective effect on the integrity of the sperm plasma membrane. Lower sperm viability was assessed in all incubated time points in control, $0.5 \%, 1 \%$ and $2 \%$ royal jelly samples to compare with viability results in samples incubated at $16^{\circ} \mathrm{C}(P<0.05)$.

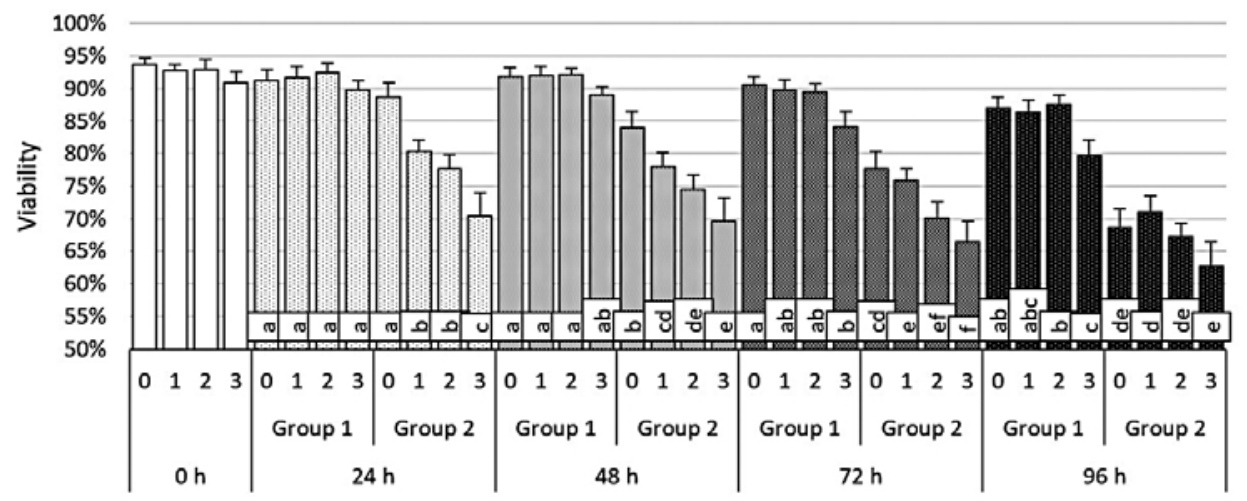

Fig. 1. The effect of royal jelly supplementation on sperm viability in liquid boar semen stored for $96 \mathrm{~h}$ at temperatures of $16{ }^{\circ} \mathrm{C}$ (Group 1$)$ and $4{ }^{\circ} \mathrm{C}$ (Group 2).

$\mathrm{a}, \mathrm{b}, \mathrm{c}, \mathrm{d}, \mathrm{e}, \mathrm{f}, \mathrm{g}$ - different letters indicate significant differences between the means at the same semen storage time $(P<0.05)$.

As shown in Table 1, the motility assay in two ways showed that the longer storage time and the lower incubation temperature results in low sperm motility. The highest significant difference in subjective motility $(12.5 \pm 1.31 \%)$ between treated and non treated samples at $16{ }^{\circ} \mathrm{C}$ was found for $2 \%$ royal jelly supplementation after $96 \mathrm{~h}$ of incubation $(P<0.05)$. Sperm motility in samples stored at $4{ }^{\circ} \mathrm{C}$ decreased rapidly with higher royal jelly concentration and longer storage time and differs significantly from the results in samples stored at $16^{\circ} \mathrm{C}$. The highest significant difference in subjective motility $(16.0 \pm 1.41 \%)$ between treated and non-treated samples at $4{ }^{\circ} \mathrm{C}$ was found also for $2 \%$ royal jelly supplementation after $96 \mathrm{~h}$ of incubation $(P<0.05)$. Objective sperm motility results were also significantly higher in samples stored at $16{ }^{\circ} \mathrm{C}$ in all royal jelly supplementations $(P<0.05)$. The storage time of samples also had a significant negative effect on subjective sperm motility results. However, sperm motility results in samples stored at $4{ }^{\circ} \mathrm{C}$ decreased significantly after $48 \mathrm{~h}$, while sperm motility results in samples stored at $16^{\circ} \mathrm{C}$ decreased significantly after $72 \mathrm{~h}(P<0.05)$. Objective sperm motility results showed the same negative impact of storage time on sperm kinematics. Lower values of all tested parameters were detected in samples stored at $4{ }^{\circ} \mathrm{C}$. 
Table 1 . The effect of royal jelly (RJ) supplementation on sperm motility, detected objectively via computerized Sperm Class Analyzer program, in diluted boar semen and stored for $24 \mathrm{~h}, 48 \mathrm{~h}, 72 \mathrm{~h}$ and $96 \mathrm{~h}$ at temperatures of $16^{\circ} \mathrm{C}$ and $4{ }^{\circ} \mathrm{C}$, respectively.

\begin{tabular}{|c|c|c|c|c|c|c|}
\hline \multirow{2}{*}{\multicolumn{2}{|c|}{ Treatment }} & \multicolumn{5}{|c|}{ Objective motility \% } \\
\hline & & \multicolumn{5}{|c|}{ Storage time } \\
\hline & & $0 \mathrm{~h}$ & $24 \mathrm{~h}$ & $48 \mathrm{~h}$ & $72 \mathrm{~h}$ & $96 \mathrm{~h}$ \\
\hline \multirow[t]{4}{*}{$16^{\circ} \mathrm{C}$} & 0\% RJ (control) & $94.3 \pm 1.54^{\mathrm{A}}$ & $92.9 \pm 1.98^{\mathrm{aAB}}$ & $88.7 \pm 2.02^{\mathrm{a}}$ & $86.2 \pm 2.99 \mathrm{aBC}$ & $83.3 \pm 3.39^{\mathrm{aC}}$ \\
\hline & $0.5 \% \mathrm{RJ}$ & $95.1 \pm 1.09^{\mathrm{aA}}$ & $91.4 \pm 1.17 \mathrm{abAB}$ & $87.5 \pm 2.58^{\mathrm{aBC}}$ & $84.5 \pm 2.62^{\mathrm{aCD}}$ & $78.1 \pm 3.33^{\mathrm{aD}}$ \\
\hline & $1 \% \mathrm{RJ}$ & $89.9 \pm 1.91 \mathrm{bA}$ & $86.7 \pm 2.64^{\mathrm{abcA}}$ & $84.8 \pm 2.23 \mathrm{aA}$ & $82.7 \pm 2.91^{\mathrm{aA}}$ & $73.2 \pm 3.82^{\mathrm{abB}}$ \\
\hline & $2 \% \mathrm{RJ}$ & $92.3 \pm 1.70^{\mathrm{A}}$ & $86.4 \pm 2.88^{\mathrm{abcAB}}$ & $83.3 \pm 3.25^{\mathrm{aAB}}$ & $77.8 \pm 2.79^{\mathrm{aB}}$ & $63.7 \pm 4.79^{\mathrm{bC}}$ \\
\hline \multirow[t]{4}{*}{$4^{\circ} \mathrm{C}$} & $0 \% \mathrm{RJ}$ (control) & $94.3 \pm 1.54^{\mathrm{A}}$ & $91.2 \pm 1.97 \mathrm{abA}$ & $70.5 \pm 4.86^{\mathrm{bB}}$ & $49.7 \pm 6.79 \mathrm{bC}$ & $45.6 \pm 4.67^{\mathrm{cC}}$ \\
\hline & $0.5 \% \mathrm{RJ}$ & $95.1 \pm 1.09^{\mathrm{aA}}$ & $85.4 \pm 2.19^{\mathrm{bcdA}}$ & $64.5 \pm 4.64$ bcB & $40.1 \pm 5.9^{\mathrm{bcC}}$ & $36.5 \pm 2.88^{\mathrm{cdC}}$ \\
\hline & $1 \% \mathrm{RJ}$ & $89.9 \pm 1.91 \mathrm{bA}$ & $82.6 \pm 2.27^{\mathrm{cdA}}$ & $61.5 \pm 5.55^{\mathrm{bcB}}$ & $34.5 \pm 6.79^{\mathrm{cC}}$ & $29.3 \pm 3.30^{\mathrm{deC}}$ \\
\hline & $2 \% \mathrm{RJ}$ & $92.3 \pm 1.70^{\mathrm{A}}$ & $79.5 \pm 3.45^{\mathrm{dA}}$ & $53.9 \pm 5.63^{\mathrm{cB}}$ & $31.9 \pm 6.92^{\mathrm{cC}}$ & $22.5 \pm 3.79^{\mathrm{eC}}$ \\
\hline
\end{tabular}

a,b,c,d,e,f - different superscripts indicate significant differences between data within the same column $(P<0.05)$.

$\mathrm{A}, \mathrm{B}, \mathrm{C}, \mathrm{D}, \mathrm{E}$ - different superscripts indicate significant differences between data within the same row $(P<0.05)$.

In order to evaluate ionic conditions in boar semen during storage, sperm $\mathrm{pH}$ was measured. The results showed the increase of sperm $\mathrm{pH}$ in all non-treated samples or samples supplemented with various royal jelly concentrations and incubated at different temperatures for $96 \mathrm{~h}$ (Fig. 2). The significant difference was observed already on the first day, just after collection and supplementation of samples with royal jelly. Supplementation of liquid boar semen with $2 \%$ royal jelly reduced sperm $\mathrm{pH}$ by $0.54 \pm 0.01(P<0.05)$. The results of $\mathrm{pH}$ in semen samples stored at $4{ }^{\circ} \mathrm{C}$ increased significantly during storage time and the highest was detected in the non-treated group after $96 \mathrm{~h}(8.12 \pm 0.03)$.

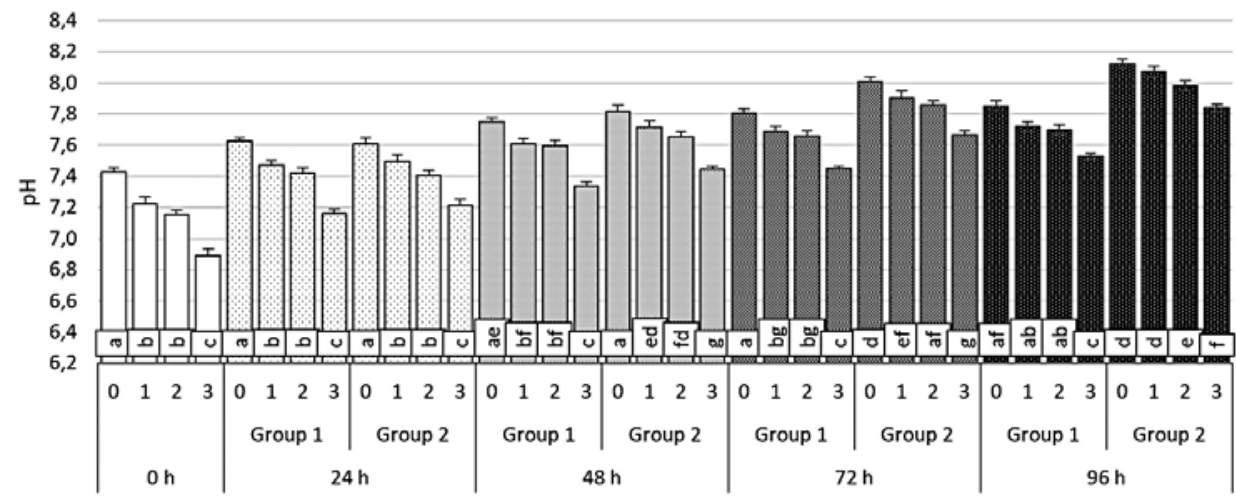

Fig. 2. The effect of royal jelly supplementation on sperm $\mathrm{pH}$ in liquid boar semen stored for $96 \mathrm{~h}$ at temperatures of $16{ }^{\circ} \mathrm{C}$ (Group 1) and $4{ }^{\circ} \mathrm{C}$ (Group 2).

$\mathrm{a}, \mathrm{b}, \mathrm{c}, \mathrm{d}, \mathrm{e}, \mathrm{f}, \mathrm{g}$ - different letters indicate significant differences between the means at the same semen storage time $(P<0.05)$.

Sperm viability, motility and $\mathrm{pH}$ results were highly intercorrelated. The highest negative correlation was observed between sperm quality parameters and $\mathrm{pH}$ detected in treated and non-treated samples at $4{ }^{\circ} \mathrm{C}$. Sperm viability $(\mathrm{r}=-0.45)$, motility subjective $(\mathrm{r}=-0.672)$ 
and motility objective $(\mathrm{r}=-0.641)$ correlated negatively with $\mathrm{pH}(P<0.05)$. There was also a significant correlation between $\mathrm{pH}$ and non-viable spermatozoa in treated and non-treated samples at $16^{\circ} \mathrm{C}(\mathrm{r}=0.157, P<0.05)$.

\section{Discussion}

In this study, we used royal jelly as an antioxidant supplementation for liquid boar semen storage. The sperm quality parameters: sperm motility and viability in this study were affected by the dose of royal jelly supplementation, semen storage temperature and storage time. Our findings in the current study indicated that by prolonging the storage and especially cold storage time, a significant reduction in the motility and viability was obtained. This reduction may be associated with the enhancement in the generation of free radicals and their negative impact on the plasma membrane lipid and protein distribution and loss of physiological function during semen dilution and storage. However, royal jelly supplementation at lower concentrations $(0.5 \%$ and $1 \%)$ for storage time of $96 \mathrm{~h}$ at $16^{\circ} \mathrm{C}$ resulted in a protective effect on cell membrane integrity. The highest viability values were found for the $1 \%$ royal jelly concentration at all storage times at a temperature of $16{ }^{\circ} \mathrm{C}$. Previous reports are in agreement with our findings. Royal jelly supplementation at lower concentrations $(0.5 \%$ and $1 \%)$ was reported to improve the ram sperm kinetics and plasma membrane functionality during liquid storage (Moradi et al. 2013). These authors also stated that the produced nitric oxide level during storage was reduced by the addition of royal jelly at low concentrations of $0.5 \%$ and $1 \%$.

Some other authors analysed the effects of supplementation of extenders with other antioxidants such as taurine, glutathione, trehalose, L-carnitine, vitamin E analogue Trolox at different concentrations for liquid ram (Bucak and Tekin 2007) and boar (Vongpralub et al. 2016) semen storage. The results are controversial and it appears that the protective effect of antioxidants depends to a large extent on the concentration and storage time. Based on the findings of authors using taurine and trehalose as an antioxidant at two concentrations of 50 and $100 \mathrm{mM}$, there were two different effects on sperm viability and other sperm quality parameters after $30 \mathrm{~h}$ of liquid storage. The additives taurine and trehalose used at small concentrations $(50 \mathrm{mM})$ played an important role in ram semen sperm protection, e.g. sperm motility, viability and membrane stabilisation of sperm cells during storage, as the higher concentrations $(100 \mathrm{mM})$ of additives the antioxidants not only failed to increase the sperm motility but even resulted in its significant reduction (Bucak and Tekin 2007). Other studies also showed the protective effects of antioxidant glutathione, vitamin $\mathrm{E}$ and L-carnitine at small concentrations $(0.1$ and $1 \mathrm{mM})$ on semen parameters during liquid boar semen storage for 10 days, however, the supplementation of semen extender with $5 \mathrm{mM}$ of vitamin $E$ had even detrimental effects on the quality of stored boar semen (Vongpralub et al. 2016). In this study, the liquid storage of semen supplemented with $2 \%$ royal jelly had a negative effect on sperm plasma membrane integrity. This can be explained by the fact that the natural substances with antioxidant effects are acting as double-edged swords, meaning that the high concentration of exogenous antioxidants may disrupt redox balance. The higher concentrations of exogenous antioxidants act as a pro-oxidant and this may be related to reaction with the physiologic level of reactive oxygen species, which is essential for optimal cellular functioning.

Another finding in this study was the lack of positive effect of royal jelly supplementation on sperm viability and motility parameters during cold storage (at $4{ }^{\circ} \mathrm{C}$ ) for $96 \mathrm{~h}$. In the present study, low storage temperature despite royal jelly supplementation negatively affected the semen quality parameters, however, another study with ram semen suggests that royal jelly supplementation at lower concentrations $(0.5 \%$ and $1 \%)$ improves the ram sperm kinematics and plasma membrane functionality during liquid and cold storage 
(Moradi et al. 2013). It could be explained by the boar sperm cells' exclusivity. It is well known that sperm cells exposed to a number of potential sources of stress (dilution, cooling, incubation) result in the damage of the sperm plasma membrane through lipid peroxidation from an increased level of reactive oxygen species. Boar sperm is more sensitive to cooling, with less tolerance to decreased temperature than bull or ram sperm. The practical storage temperature of extended boar semen $\left(15-20{ }^{\circ} \mathrm{C}\right)$ is acceptable and a critical cold shock temperature for extended semen is possibly lower than $12{ }^{\circ} \mathrm{C}$ as expressed by decreased sperm motility (Althouse et al. 1998). It is well known that several factors such as storage temperature and length, dilution rate, extender composition and even rotation of semen tubes may influence the quality of cooled boar semen doses (Johnsson et al. 2000; Pinart et al. 2015; Schulze et al. 2015a; Schulze et al. 2015b).

Another factor that could modify seminal quality is the contact of extended semen with environmental air (Ribeiro et al. 2016). The authors observed that the $\mathrm{pH}$ of semen doses increased as the amount of air increased within the tubes. There are only a few studies that analyzed the effect of air presence on semen $\mathrm{pH}$ and semen quality parameters (Ribeiro et al. 2016) and the rise of $\mathrm{pH}$ during storage of extended porcine semen (Vyt et al. 2007). The authors found that air within sperm tubes affects the quality of extended semen during storage, resulting in an increase of $\mathrm{pH}$ and a decrease in motility preservation. Royal jelly is a highly acidic ( $\mathrm{pH} 3.4-4.5)$ substance and this was obvious in the present results where different royal jelly concentration supplementation within sperm containing tubes resulted in different values of $\mathrm{pH}$. It was hypothesized that the rise of $\mathrm{pH}$ during liquid boar semen storage was not so fast due to acidic royal jelly supplementation. However, our results are in agreement with the previous finding. The results of our study showed an increase of sperm $\mathrm{pH}$ in all non-treated samples or samples supplemented with various royal jelly concentrations and incubated at different temperatures for $96 \mathrm{~h}$, and a decrease in sperm viability and motility was detected using two (ordinary and computerized) methods. Computerized measurements of sperm motility can detect even minimal changes in sperm motility. This could be explained by the existence of a bicarbonate buffering system in the extender, which leads to a loss of $\mathrm{CO}_{2}$ from the diluted semen to the air compartment within the tube, removes protons from the extender and leads to accelerated alkalinization of the semen suspension (Schulze et al. 2015b; Ribeiro et al. 2016). Anyway, a rise in $\mathrm{pH}$ was observed in all samples and especially in cold storage samples. This could be explained by adding air to the tubes during the daily semen testing.

In conclusion, the air conditions and semen $\mathrm{pH}$ influence semen quality during the storage period and the addition of antioxidants, even at small concentrations, can improve sperm function during storage. The results of the present experiment showed that royal jelly supplementation at low concentrations $(0.5$ and $1 \%)$ can improve boar semen quality parameters including total motility and viability during liquid storage at $16^{\circ} \mathrm{C}$ for $96 \mathrm{~h}$, but no protective effect on sperm functionality and kinematics was found at $4{ }^{\circ} \mathrm{C}$. The protective effects of royal jelly are related to its antioxidant property, which could be provided at proper concentration and it is based on the duration of storage time.

\section{References}

Abd-Allah SM 2012: Effect of royal jelly on the fertilizing ability of buffalo spermatozoa in vitro. J Buff Sci 1: 1-4

Ahmadnia H, Sharifi N, Alizadeh S, Roohani Z, Kamalati A, Marjan S 2015: Wonderful effects of royal jelly on treatment of male-factor related infertility. Austin J Reprod Med Infertil 2: 1031

Alcay S, Toker MB, Onder NT, Gokce E 2017: Royal jelly supplemented soybean lecithin-based extenders improve post-thaw quality and incubation resilience of goat spermatozoa. Cryobiology 74: 81-85

Allai L, Benmoula A, Maia MS, Nasser B, Amiri BE 2018: Supplementation of ram semen extender to improve seminal quality and fertility rate. Anim Reprod Sci 192: 6-17

Althouse GC, Wilson ME, Kuster C, Parsley M 1998: Characterization of lower temperature storage limitations of fresh-extended porcine semen. Theriogenology 50: 535-543 
Amirshahi T, Najafi G, Nejati V 2014: Protective effect of royal jelly on fertility and biochemical parameters in bleomycin-induced male rats. Iran J Reprod Med 12: 209-216

Bucak MN, Tekin N 2007: Protective effect of taurine, glutathione and trehalose on the liquid storage of ram semen. Small Rumin Res 73: 103-108

Estienne MJ, Harper AF, Day JL 2007: Characteristics of sperm motility in boar semen diluted in different extenders and stored for seven days at $18^{\circ} \mathrm{C}$. Reprod Biol 7: 221-231

Ghanbari E, Nejati V, Najafi G, Khazaei M, Babaei M 2015: Study on the effect of royal jelly on reproductive parameters in streptozotocin-induced diabetic rats. Int J Fertil Steril 9: 113-120

Hashimoto M, Kanda M, Ikeno K, Hayashi Y, Nakamura T 2005: Oral administration of royal jelly facilitates mRNA expression of glial line-derived neurotrophic factor and neurofilament $h$ in the hippocampus of the adult mouse brain. Biosci Biotechnol Biochem 69: 800-805

Hattori N, Nomoto H, Fukumitsu H, Mishima S, Furukawa Sh 2007: Royal jelly-induced neurite outgrowth from rat pheochromocytoma PC12 cell requires integrin signal independent of activation of extracellular signal regulated kinases. Biomed Res 28: 139-146

Januskauskas A 2010: Reproduction and Insemination of Farm Animals. Methodological guidelines (in Lithuanian). Kaunas, Lithuania. 42 p.

Johnsson LA, Weitze KF, Fiser P, Maxwell WMC 2000: Storage of boar semen. Anim Reprod Sci 62: 143-172

Kaeoket K, Srisowanna T, Wichaidit U, Chanapiwat P, Manee-in S 2010: Comparative study on six different long term commercial extenders for fresh boar semen. Thai J Vet Med 40: 257-263

Kamakura M, Fukuda T, Fukushima M, Yonekura M 2001: Storage dependent degradation of 57-kDa protein in royal jelly: a possible marker for freshness. Biosci Biotechnol Biochem 65: 277-284

Matsui T, Yukiyoshi A, Doi S, Sugimoto H, Yamada H, Matsumoto K 2002: Gastrointestinal enzyme production of bioactive peptides from royal jelly protein and their antihypertensive ability in SHR. J Nutr Biochem 13: 80-86

Moradi A, Malekinejad H, Farrokhi-Ardabili F, Bernousi I 2013: Royal jelly improves the sperm parameters of ram semen during liquid storage and serves as an antioxidant source. Small Rum Res 113: 346-352

Morita H, Ikeda T, Kjita K, Fujioka K, Mori I, Okada H, Uno Y, Ishizuka T 2012: Effect of royal jelly ingestion for six months on healthy volunteers. Nutr J 11: 77

NakajimaY, Tsuruma K, Shimazawa M, Mishima S, Hara H 2009: Comparison of bee products based on assays of antioxidant capacities. Complement Altern Med 9: 1-4

Petelin A, Kenig S, Kopinč R, Deželak M, Bizjak MČ, Pražnikar 2019: Effects of royal jelly administration on lipid profile, satiety, inflammation, and antioxidant capacity in asymptomatic overweight adults. Evid Based Complement Alternat Med 2019: Article ID 4969720, 11 p.

Petruska P, Capcarova M, Sutovsky P 2014: Antioxidant supplementation and purification of semen for improved artificial insemination in livestock species. Turk J Vet Anim Sci 38: 643-652

Pinart E, Yeste M, Prieto-Martínez N, Reixach J, Bonet S 2015: Sperm quality and fertility of boar seminal doses after 2 days of storage: Does the type of extender really matter? Theriogenology 83: 1428-1437

Ribeiro CV, Moroni JL, Menegat MB, Mellagi APG, Bernardi ML, Wentz I, Bortolozzo FP 2016: The influence of air contact on the quality of extended boar semen. Acta Sci Vet 44:1423

Schulze M, Rüdiger K, Jung M, Grossfeld R 2015a: Use of refractometry as a new management tool in AI boars centers for quality assurance of extender preparations. Animal Reprod Sci 152: 77-82

Schulze M, Rüdiger K, Waberski D 2015b: Rotation of boar semen doses during storage affects sperm quality. Reprod Dom Anim 50: 684-687

Shahzad Q, Mehmood MU, Khan H, ul Husna A, Qadeer S, Azam A, Naseer Z, Ahmad E, Safdar M, Ahmad M 2016: Royal jelly supplementation in semen extender enhances post-thaw quality and fertility of Nili-Ravi buffalo bull sperm. Anim Reprod Sci 167: 83-88

Sutkeviciene N, Kasperaviciute G, Banys A, Rekesiute A, Zilinskas H 2018: Extended boar semen storage associated with lower sow's fertility and lower numbers of piglets born alive. Vet Med Zoot 76: 70-75

Vongpralub T, Thananurak P, Sittikasamkit C, Chuawongboon P, Duangjinda M, Boonkum W, Chankitisakul V 2016: Comparison of effects of different antioxidants supplemented to long-term extender on boar semen quality following storage at $17^{\circ} \mathrm{C}$. Thai J Vet Med 46: 119-126

Vyt P, Maes D, Sys SU, Rijsselaere T, Soom AV 2007: Air contact influences the $\mathrm{pH}$ of extended porcine semen. Reprod Dom Anim 42: 218-220

Zahmatkesh E, Najafi G, Nejati V, Heidari R 2014: Protective effect of royal jelly on sperm parameters and testosterone level and lipid peroxidation in adult mice treated with oxymetholone. Avicenna J Phytomed 4: $43-52$ 